\title{
A selective optical chemical sensor for 2,6-dinitrophenol based on fluorescence quenching of a novel functional polymer
}

\author{
Xu Wang, Hulie Zeng, Lixia Zhao, Jin-Ming Lin* \\ State Key Laboratory of Environmental Chemistry and Ecotoxicology, Research Center for Eco-Environmental Sciences, \\ Chinese Academy of Sciences, P.O. Box 2871, Beijing 100085, China \\ Received 25 September 2005; received in revised form 31 December 2005; accepted 4 January 2006 \\ Available online 13 February 2006
}

\begin{abstract}
A bifurcated optical fiber based chemical sensor for continuous monitoring of 2,6-dinitrophenol (2,6-DNP) has been proposed based on the reversible chemical reaction between a novel functional poly(vinyl chloride) (PVC) as the sensing material and the analytes. The functional PVC (FPVC), containing a fluorescent curcumin moiety, was synthesized by the nucleophilic substitution of a fraction of the chlorine atoms bound to the PVC backbone by curcumin. When plasticized in a membrane of $5 \mu \mathrm{m}$ thickness, FPVC extracts 2,6-DNP from aqueous solution into the bulk membrane phase and reacts with the analyte to form a complex with low fluorescence efficiency through hydrogen bonding. Formation of the complex gave a significant fluorescence quenching which is suitable for signalling the occurrence of the host-guest interaction. At $\mathrm{pH} 3.50$, the sensor exhibits a dynamic detection range from $2.5 \times 10^{-6}$ to $7.0 \times 10^{-3} \mathrm{~mol} \mathrm{~L}^{-1}$ with a limit of detection of $1.0 \times 10^{-6} \mathrm{~mol} \mathrm{~L}-1$. As $2,6-\mathrm{DNP}$ can provide an optimal space geometry matches to the formation of hydrogen bonds, the sensor shows excellent selectivity for 2,6-DNP over other nitrophenols. The forward and reverse response time $\left(t_{95}\right)$ of the sensor both was within $1 \mathrm{~min}$. The repeatability, reproducibility, and lifetime of the sensor were also satisfied. The sensor was applied to determine 2,6-DNP in water samples successfully.
\end{abstract}

(C) 2006 Elsevier B.V. All rights reserved.

Keywords: Optical chemical sensor; 2,6-Dinitrophenol; Fluorescence quenching; Functional polymer

\section{Introduction}

In recent years, the ever-increasing number of organic toxic compounds being detected in human environment has risen concern about the contamination of environment resources. Among various toxic compounds, nitrophenols are widely presented and persistent in the environment, especially in waters $[1,2]$. They have great potential toxicities of carcinogenesis, teratogenesis, and mutagenesis such that are considered to be hazardous wastes and priority toxic pollutants by U.S. Environmental Protection Agency (EPA) [3]. 2,6-Dinitrophenol (2,6-DNP) is one of the six possible dinitro phenol forms used in the synthesis of dyes, picric acid, picramic acid, wood preservatives, diaminophenoldihydrochloride (a photographic developer), explosives, and insecticides [4]. A few literatures about the determination of 2,6-DNP are focused on conventional chromatographic meth-

\footnotetext{
* Corresponding author. Fax: +86 1062841953.

E-mail address: jmlin@mail.rcees.ac.cn (J.-M. Lin).
}

ods [5-7], which suffer from various disadvantages such as discontinuity, time consumption, analyte destruction, and high running cost. Thus there is still a significant demanding for the fabrication of a new optical fiber chemical sensor for 2,6-DNP, since the user-friendly optochemical sensors can offer advantages in terms of no sample pretreatment, small size, low cost, and quick signal transmission. The determination using an optical sensor can be performed through immobilizing the sensing materials on a solid-state support to form a chemically recognized membrane which was connected with a transducer device. Since nitrophenols are known to be good electron acceptors and quenchers, the quenching effect of nitrophenols on some fluorescent substances have been used to fabricate optical sensors for nitrophenols [8-10].

In the recent years, polymers have gained tremendous recognition in the field of artificial sensor in the goal of gaining better selectivity and fast measurement $[11,12]$. But as one of the most widely used polymers, PVC was mainly used as the plasticized matrices for the dispersion of sensing molecules within it and the modified PVC was rarely used to behave a sensing substance. 
Fortunately, the studies on the functionalization of PVC through nucleophilic substitution have been carried out [13-15]. These functional PVC (FPVC) have been successfully applied to prepare surfactant-selective electrode [13], reduce plasticizer migration [14], and construct novel biomaterials [15].

This paper describes our efforts focused on developing a solid-state chemical sensor for 2,6-DNP in water using a novel FPVC as the sensing substance. The FPVC was synthesized by the nucleophilic substitution reaction on PVC backbone with curcumin. The design of the approach consists of electrondonating curcumin moiety as a 2,6-DNP-bonding site as well as a fluorescence site, where the hydrogen bonding is responsible for the quenching of the fluorescence emission of curcumin moiety. The sensing characteristics of the proposed sensor were investigated. The steric effect or spatial matching occurred between host and guest was proved to be the primary factor that dominated the complex formation. FPVC was readily used as the sensing substance in an optic fiber based chemical sensor for 2,6-DNP. Compared with the physically embedded curcumin membrane with PVC as the matrixes, the proposed FPVC-based membrane showed markedly better sensing performance in terms of sensitivity, selectivity, response time, and lifetime. The proposed sensor was used to determine 2,6-DNP in water samples satisfactorily. To our best knowledge, the functionally substituted polymer based fluorescence sensor was rarely reported.

\section{Experimental}

\subsection{Apparatus}

${ }^{1} \mathrm{H}$ NMR spectra were recorded on an ARX-400 (Bruker, $400 \mathrm{MHz}$, Germany) spectrometer in DMSO- $d_{6}$ with tetramethylsilane as internal standard. Infrared spectra were obtained from a NEXUS 670-FT-IR (Thermo Nicolet Corporation, Massachusetts, USA) spectrophotometer with $\mathrm{KBr}$ disk. Elemental analysis was performed on a Flash EA 1112 elemental analyzer (Thermoquest, Italy). A Dektak 8 surface profiler (Digital Instruments, California, USA) was used to determine the film thickness by scanning the edge of a small scratch that was applied to the sensing membrane that was coated to a circular quartz plate. UV-visible measurements were performed on a Shimadzu UV2401 UV-visible spectrophotometer (Shimadzu, Kyoto, Japan). All fluorescence measurements were carried out on a Hitachi F-2500 fluorescence spectrometer (Hitachi, Tokyo, Japan) with excitation and emission slits set at 5 and $10 \mathrm{~nm}$, respectively. A homemade PTFE flow cell and a bifurcated optical fiber $(50+50$ quartz fibers, diameter $6 \mathrm{~mm}$ and length $1.2 \mathrm{~m}$ ) were used for the sensing measurements (Fig. 1). The quartz plate with the sensing membrane on it was mounted in the flow cell. The membrane side is facing the cell chamber with the circulating sample solution sweeping over the membrane driven by a peristaltic pump (Lange Instruments, Baoding, China). The opposite side of the quartz plate tightly matching the common end of the optical fiber. Data processing was performed on a Pentium III computer with software of Sigma plot. For pH measurements, an Orion Model $828 \mathrm{pH}$ meter (Massachusetts, USA) was used. A spin-on device [12] was used to prepare the membrane.

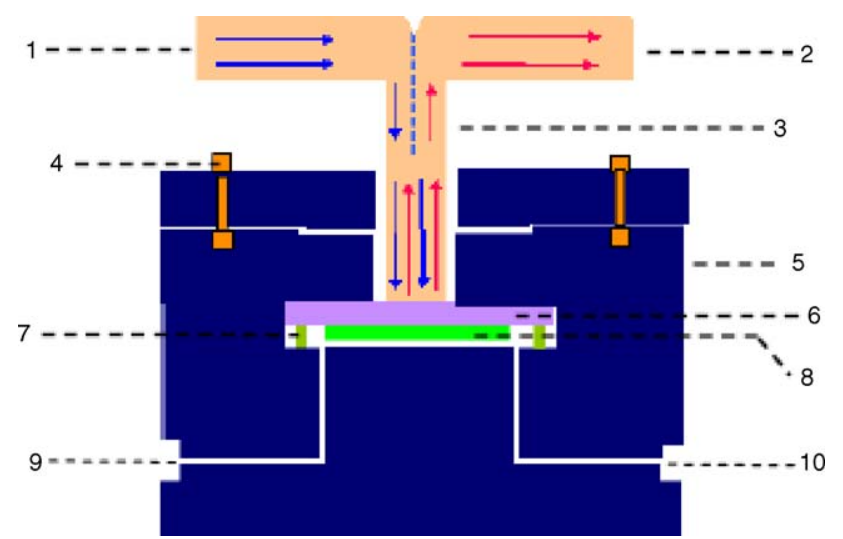

Fig. 1. Schematic diagram of the flow cell arrangement: (1) excitation light, (2) signal light, (3) bifurcated optical fiber, (4) screw cap, (5) cell body, (6) quartz glass slide, (7) O silicon ring, (8) sensing membrane, (9) sample inlet, and (10) sample outlet.

\subsection{Chemicals}

Analytical reagent grade chemicals were used unless indicated otherwise. The following reagents were used for FPVC synthesis and membrane preparation: high molecular weight PVC was purchased from Sigma (St. Louis, USA). Curcumin was from Shanghai Chemical Factory (Shanghai, China). Hexadecyltrimethyl ammonium bromide (CTAB), tetrahydrofuran (THF), tributyl phosphate (TBP), diisooctyl sebacate (DOS), and dioctyl phthalate (DOP) were obtained from Beijing Chemical Factory (Beijing, China).

2,6-DNP, $o$-nitrophenol (o-NP), $m$-nitrophenol $(m$-NP), $p$-nitrophenol ( $p$-NP), 2,4-dinitrophenol (2,4-DNP), 2,4,6trinitrophenol (2,4,6-TNP), and other phenols used were from Beijing Chemical Factory (Beijing, China). The stock solutions of nitrophenols were prepared by dissolving the appropriate amount of each sample in methanol. Working solutions were prepared by successive dilution of the stock solutions with $0.1 \mathrm{M}$ sodium acetate-hydrochloric acid buffer solution of $\mathrm{pH} 3.50$. The ultra high purity deionized water used in the experiment was obtained from Easypure water purification system with a $0.2 \mu \mathrm{m}$ fiber filter (Barnstead, USA).

\subsection{Substitution reaction of $P V C$ with curcumin}

$0.5 \mathrm{~g}$ curcumin $(1.36 \mathrm{mmol})$ was added to a $40 \mathrm{~mL}$ sodium carbonate-sodium bicarbonate buffer solution $\left(0.1 \mathrm{~mol} \mathrm{~L}^{-1}, \mathrm{pH}\right.$ $10.0)$ at room temperature and stirred for $20 \mathrm{~min}$. Then a $50 \mathrm{~mL}$ THF solution of PVC resin $(2 \mathrm{~g}, 0.01 \mathrm{mmol})$ was added. The resulting red brown solution was heated and stirred for $30 \mathrm{~min}$ at $50^{\circ} \mathrm{C}$, after which, calculated amount $(0.1 \mathrm{~g}, 0.27 \mathrm{mmol})$ of $\mathrm{CTAB}$ as phase-transfer catalyst was added dropwise. After stirring the mixture at $80^{\circ} \mathrm{C}$ for $5 \mathrm{~h}$, THF was removed under reduced pressure. A brown color precipitate developed immediately. The products were collected by filtration, subjected to mild sonication in a bath type sonicator for 3 min to remove any surface adhering reactants, and then dried in an air oven at $80{ }^{\circ} \mathrm{C}$ to constant weight. Product: ${ }^{1} \mathrm{H}$ NMR $[16,17](400 \mathrm{MHz}$, DMSO- $d_{6}$ ) $2.23-2.34 \mathrm{ppm}$ (br m, 20H, methylene protons of 
$-\left[\mathrm{CH}_{2}-\mathrm{CHCl}\right]_{n}-$ ), $4.34-4.45 \mathrm{ppm}$ (br m, $10 \mathrm{H}$, methyne protons of $\left.-\left[\mathrm{CH}_{2}-\mathrm{CHCl}\right]_{n}-\right), 9.65 \mathrm{ppm}$ (s, $2 \mathrm{H}$, hydroxy $\mathrm{H}$ of benzene ring), 7.14-7.56 ppm (m, 6H, ortho- and meta- $\mathrm{H}$ of the substituted benzene ring), $6.74-6.83 \mathrm{ppm}(\mathrm{m}, 4 \mathrm{H},-\mathrm{HC}=\mathrm{CH}-$ double bond $\mathrm{H}), 6.06 \mathrm{ppm}$ (s, $1 \mathrm{H}$, hydroxy $\mathrm{H}$ of enol form of curcumin moiety), $3.82 \mathrm{ppm}$ (s, 6H, methoxy-H); FT-IR (KBr disk) 2910, 2850, 1430, 1250, 964, 768, 690, 636, 611 $\mathrm{cm}^{-1}$ (C-C and C-H stretching vibrations of PVC), 611, 636, 690, $768 \mathrm{~cm}^{-1}$ (stretching vibrations of $\mathrm{C}-\mathrm{Cl}$ ) $[18,19], 845 \mathrm{~cm}^{-1}$ (adjoining hydrogens at benzene ring), $1590 \mathrm{~cm}^{-1}$ (benzene ring skeleton vibration), $1620 \mathrm{~cm}^{-1}(-\mathrm{C}=\mathrm{C}$ - stretching vibration of benzene ring), $3640 \mathrm{~cm}^{-1}$ (C-O-H stretching vibration); UV spectra $\lambda_{\max }(\mathrm{THF}): 426 \mathrm{~nm}$.

\subsection{Preparation of sensing membrane}

The sensing membrane solution was prepared by dissolving a mixture of $50 \mathrm{mg}$ of FPVC and $200 \mathrm{mg}$ of TBP in $2 \mathrm{~mL}$ of freshly distilled THF. A circular quartz plate of $25 \mathrm{~mm}$ diameter was mounted on the spin-on device and then rotated at a frequency of $800 \mathrm{rpm}$. Using a syringe, $0.2 \mathrm{~mL}$ of the membrane solution was sprayed to the center of the plate. After a spinning time of $4 \mathrm{~s}$, a membrane of $5 \mu \mathrm{m}$ thickness, which was determined by the surface profiler [20], was then coated on the quartz plate. The membrane was stored in buffer solution when not used.

\subsection{Measurement procedure}

Two arms of the bifurcated optical fiber were fixed in the detecting chamber of the spectrofluorimeter to carry the excitation and emission light. The fluorescence measurements were carried out at the maximum excitation wavelength of $460 \mathrm{~nm}$ and the maximum emission wavelength of $503 \mathrm{~nm}$. The sample solution was fed through the detecting chamber of the flow cell by the peristaltic pump at a rate of $2.0 \mathrm{~mL} \mathrm{~min}^{-1}$. After each measurement, the flow cell was washed with blank buffer solution until the fluorescence intensity of the sensor reached the original blank value.

\section{Results and discussion}

\subsection{Elemental analysis}

The elemental analysis presents us the C\% of PVC and FPVC with $38.57 \%$ and $39.82 \%$, respectively, from which a $1: 120$ number ratio of curcumin molecules to $-\left[\mathrm{CH}_{2} \mathrm{CHCl}\right]-$ units in FPVC was calculated, which corresponds to about $4.5 \%$ covalently bound curcumin in $1 \mathrm{~g}$ of FPVC. According to the molar absorptivity of curcumin at $423 \mathrm{~nm}\left(151.8 \mathrm{~cm}^{-1} \mathrm{mg}^{-1} \mathrm{~mL}\right)$ in THF, $1 \mathrm{~g}$ of the novel polymer contains $4.0 \%$ of curcumin [21].

\section{2. $p K_{a}$ determination}

In order to testify the formation of FPVC, the absorption spectra at various acidities of the polymer were studied and its $\mathrm{p} K_{\mathrm{a}}$ was determined according to reported method [22]. The $\mathrm{p} K_{\mathrm{a}}$ of FPVC, characterized by a difference of those two values of curcumin reported $(8.05 \pm 0.05,10.41 \pm 0.05)$ [23], has only

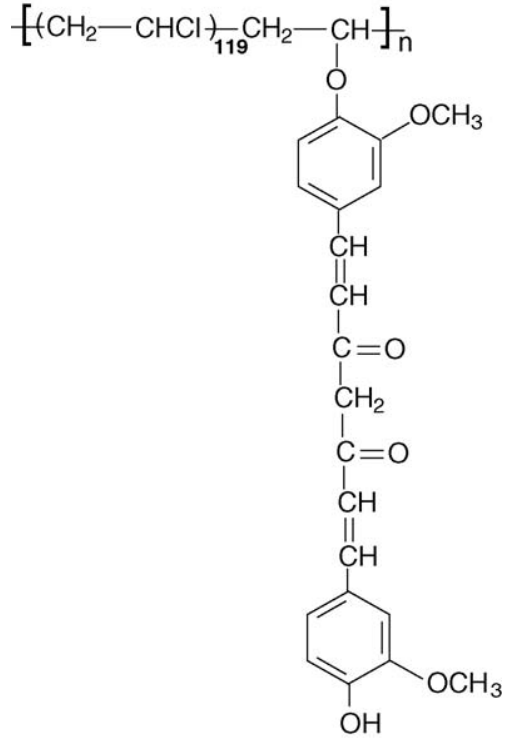

Scheme 1. The molecular structure of novel FPVC.

one value and was calculated to be 10.72 . The results indicated that PVC was nucleophilic attacked by one hydroxyl group of curcumin and curcumin was attached to the backbone of the polymer, which was consistent with the conclusion obtained from ${ }^{1} \mathrm{H}$ NMR spectra, FT-IR spectra and elemental analysis. Thus the molecular structure of FPVC was drawn and shown in Scheme 1.

Since FPVC was found to show excellent membrane formability with plasticizers, there was no need to use PVC as matrixes in the fabrication of sensing membrane.

\subsection{Optical properties of FPVC}

The absorption spectra (not shown here) of FPVC $\left(\lambda_{\max }=426 \mathrm{~nm}\right)$ in sensing membrane redshifted $3 \mathrm{~nm}$ compared with curcumin in tributyl phosphate plasticized PVC membrane $\left(\lambda_{\max }=423 \mathrm{~nm}\right)$. The reason for this perhaps was the electron-donating effect experienced by curcumin moiety produced through adjacent electron-offering alkyl backbone of the polymer, which decreased the electronic energy level of curcumin.

Fig. 2 shows the fluorescence spectra of the sensing membrane exposed to a solution containing different concentrations of 2,6-DNP, which are recorded at $\lambda_{\mathrm{ex}}=460 \mathrm{~nm}, \lambda_{\mathrm{em}}=503 \mathrm{~nm}$. Owing to the conjugated double bond system and the high mobility of its $\pi$-electrons, curcumin moiety exhibits fluorescence emission at $503 \mathrm{~nm}$ when excited by $460 \mathrm{~nm}$ radiation. From Fig. 2, one can see that the fluorescence intensities of the sensing membrane decrease with increase of the concentration of 2,6-DNP, which constitutes the basis for the determination of 2,6-DNP with the optical fiber sensor proposed in this paper.

\subsection{Optimization of membrane compositions}

Since plasticization can increase the mobility of polymer segments to improve the rate of guest extraction into and diffusion 


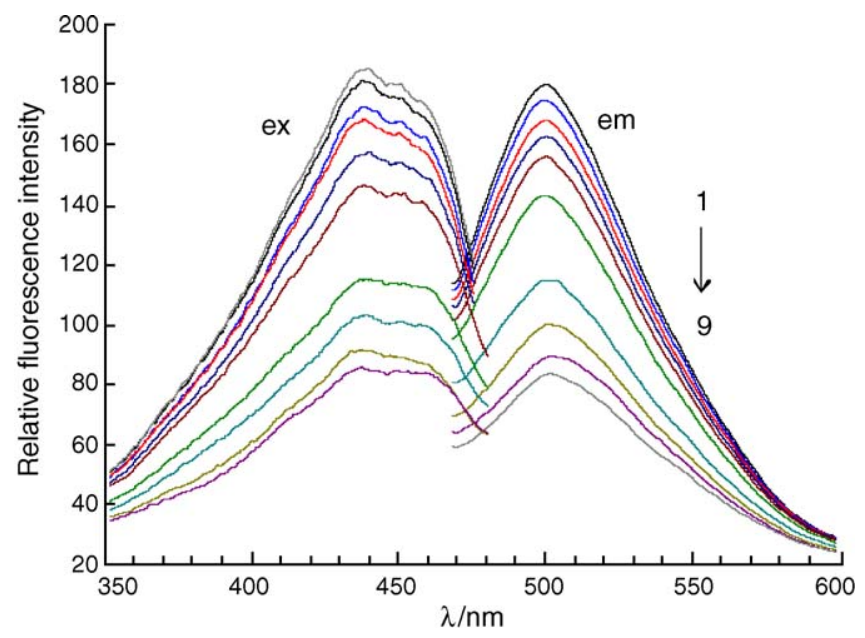

Fig. 2. Fluorescence spectra of the sensing membrane in the presence of different concentrations of 2,6-DNP at pH 3.50: (1) 0 ; (2) $1.0 \times 10^{-6}$; (3) $5.0 \times 10^{-6}$; (4) $1.0 \times 10^{-5}$; (5) $5.0 \times 10^{-5}$; (6) $1.0 \times 10^{-4}$; (7) $5.0 \times 10^{-4}$; (8) $1.0 \times 10^{-3}$; (9) $5.0 \times 10^{-3} ;(10) 8.0 \times 10^{-3} \mathrm{~mol} \mathrm{~L}^{-1}\left(\lambda_{\mathrm{ex}}=460 \mathrm{~nm}, \lambda_{\mathrm{em}}=503 \mathrm{~nm}\right)$.

throughout the film [24], as well as increase the workability, flexibility, and distensibility of the film, several membrane compositions were investigated by selecting appropriate plasticizers and varying the ratio of plasticizers to FPVC. A sensing membrane made of different plasticizers, such as tributyl phosphate (TBP), diisooctyl sebacate (DOS), and dioctyl phthalate (DOP) were prepared. Membranes consisting of TBP show the best response to 2,6-DNP and the longest lifetime. When the amount of FPVC for immobilizing was $50 \mathrm{mg}$, the optimal amount of TBP was found to be $200 \mathrm{mg}$ (Table 1).

\subsection{Characteristics of the optical membrane}

\subsubsection{Determination of the complex ratio and the equilibrium constant}

Based on an operation principle reported [25], the relationship between response parameter, $\alpha$, and 2,6-DNP concentration $\left[\mathrm{G}_{(\mathrm{aq})}\right]$ can be represented as

$\frac{\alpha^{n}}{1-\alpha}=\frac{1}{n K C_{\mathrm{H}}^{n-1}\left[\mathrm{G}_{(\mathrm{aq})}\right]^{m}}$

where $m$ and $n$ are the complexing number of 2,6-DNP and FPVC, respectively. $C_{\mathrm{H}}$ and $K$ refer to the total amount of

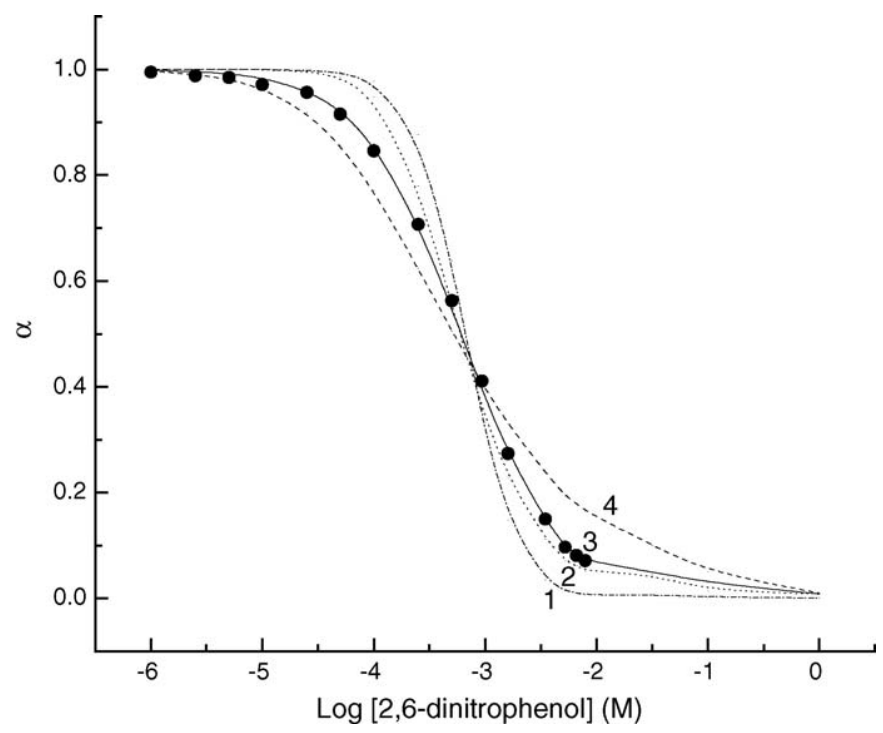

Fig. 3. Response parameter values $(\alpha)$ at $460 / 503 \mathrm{~nm}$ as a function of the logarithm of 2,6-DNP concentration at $\mathrm{pH} 3.50$. Theoretical response of 2,6-DNP as predicated by Eq. (1). The experimental data were fitted to the equation with the different complex ratios and equilibrium constant: (1) $n: m=1: 2, K=7.7 \times 10^{5}$; (2) $n: m=2: 2, K=1.2 \times 10^{6}$; (3) $n: m=1: 1, K=2.0 \times 10^{3}$ (best fit); (4) $n: m=2: 1$, $K=2.2 \times 10^{6}((\bullet)$ experimentally observed data points $)$.

FPVC in membrane and the overall equilibrium constant, respectively. Eq. (1) is the basis of the quantitative determination of 2,6-DNP in aqueous solution by using the proposed sensor. The experimental data were fitted to Eq. (1) by changing the ratio of $n$ to $m$ and adjusting the overall equilibrium constant, $K$. Fig. 3 shows the fitted curves that represents the experimental data for 2,6-DNP. The curve referring to the $1: 1$ complex ratio and $K=2.0 \times 10^{3}$ is the best one fitted to the experimental data (Fig. 3, solid line 3 ). The best-fitting curve can serve as the calibration curve for the determination of 2,6-DNP.

\subsubsection{Effect of $\mathrm{pH}$ and flow rate}

The effect of solution $\mathrm{pH}$ and flow rate on $\alpha$ and response time, $t$, was investigated over a wide $\mathrm{pH}$ range from 2.0 to 12.0 and flow rate range from 0.5 to $4.5 \mathrm{~mL} \mathrm{~min}^{-1}$ in the presence of $5.0 \times 10^{-5} \mathrm{~mol} \mathrm{~L}^{-1} 2,6$-DNP. The blank fluorescence of the sensing membrane itself was found to be independent of $\mathrm{pH}$ from 2.0 to 10.5. Solutions at $\mathrm{pH}>10.8$ caused FPVC to be dissolved

Table 1

Composition of the membrane cocktail and the response behavior of the sensing membrane at $\mathrm{pH} 3.50^{\mathrm{a}}$

\begin{tabular}{llllr}
\hline Membrane number & Plasticizer $(\mathrm{mg})$ & Working range $\left(\mathrm{mol} \mathrm{L}^{-1}\right)$ & Detection limit $^{\mathrm{b}}\left(\mathrm{mol} \mathrm{L}^{-1}\right)$ & Lifetime $^{\mathrm{c}}($ times $)$ \\
\hline 1 & DOS, 200 & $7.8 \times 10^{-5}$ to $3.7 \times 10^{-3}$ & $2.5 \times 10^{-5}$ & 80 \\
2 & DOP, 200 & $9.8 \times 10^{-5}$ to $1.1 \times 10^{-3}$ & $3.6 \times 10^{-5}$ & 100 \\
3 & TBP, 100 & $3.4 \times 10^{-6}$ to $8.5 \times 10^{-3}$ & $2.0 \times 10^{-6}$ & 100 \\
4 & TBP, 200 & $2.5 \times 10^{-6}$ to $7.0 \times 10^{-3}$ & $1.0 \times 10^{-6}$ & $>250$ \\
5 & TBP, 300 & $4.0 \times 10^{-6}$ to $4.0 \times 10^{-3}$ & $1.3 \times 10^{-6}$ & 150 \\
\hline
\end{tabular}

${ }^{a}$ Each membrane cocktail contains $50 \mathrm{mg}$ of FPVC and the listed amount of plasticizer, which were diluted to $2 \mathrm{~mL}$ with fresh distilled THF.

b The detection limit was defined as $\alpha=0.99$.

c The lifetime was defined as the usage times of the sensing membrane that produced fluorescence signal changes less than 5\% [31]. 
out from the PVC membrane because of its $\mathrm{p} K_{\mathrm{a}}$ of 10.72 . Since the $\mathrm{p} K_{\mathrm{a}}$ of 2,6-DNP is approximately 3.68 [26], the ionization of $2,6-\mathrm{DNP}$ was inhibited at $\mathrm{pH}<4.2$ and $\alpha$ remained a constant. The extent of 2,6-DNP ionization was increased at $\mathrm{pH}>4.2$ so that the ability to form complex with FPVC was weakened and $\alpha$ gradually increased. In the tested $\mathrm{pH}$ range, $t$ increased only from 46 to $48 \mathrm{~s}$ with increasing $\mathrm{pH}$. So $0.1 \mathrm{~mol} \mathrm{~L}^{-1}$ sodium acetate-hydrochloric acid buffer solution was used to adjust solution $\mathrm{pH}$ at 3.50. The flow rate had almost no effect on $\alpha$ and $\alpha$ remained a constant with variation of the flow rate. The response time $t$ was apparently influenced by the flow rate with a variation from 53 to $45 \mathrm{~s}$ when the flow rate was increased from 0.5 to $4.5 \mathrm{~mL} \mathrm{~min}^{-1}$, which was resulted from increasing of the renew rate of the sensing membrane interface and will strengthen the migration process of 2,6-DNP from the aqueous solution to the membrane phase. In order to avoid the leakage of the sensing substance in the membrane at high flow rate, a flow rate of $2.0 \mathrm{~mL} \mathrm{~min}^{-1}$ was finally selected as a compromise among response time and membrane stability.

\subsubsection{Dynamic response behavior}

With the optimum conditions, the sensor exhibits a dynamic detection range from $2.5 \times 10^{-6}$ to $7.0 \times 10^{-3} \mathrm{~mol} \mathrm{~L}^{-1}$ $(0.05<\alpha<0.95)$ [27] and limit of detection of $1.0 \times 10^{-6}$ mol L ${ }^{-1}$. The response behavior of the sensor to 2,6-DNP was shown in Fig. 4. As can be seen, under the optimum conditions, the forward response time (going from lower to higher 2,6-DNP concentrations), $t_{95}$ (time needed for $95 \%$ of the total signal change to occur) was within $1 \mathrm{~min}$, whereas the time for the reverse response was in the range of 1 min over the entire concentration range. Thus the proposed sensor was independent of the order of concentration change, and it was quite reversible and no noticeable hysteresis effect was observed, which indicated that the migration rate of the analyte in the dynamic process was fast [28].

Clearly, both the polymer cavity size and the binding strength can affect the diffusion rate of analytes in a polymer film

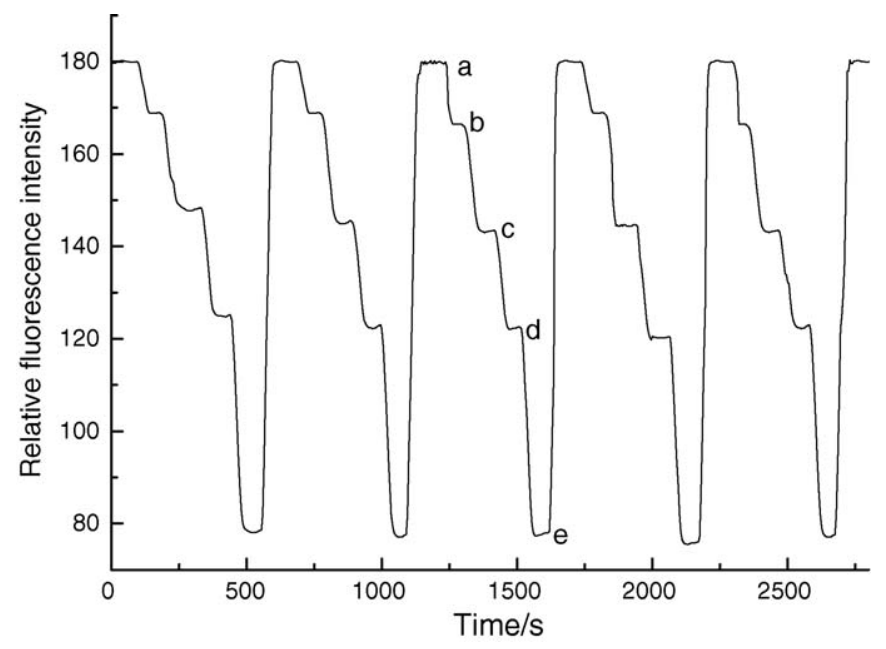

Fig. 4. The time-dependent response of the sensor. The sensor is alternatively exposed to (b) $2.5 \times 10^{-6}$, (c) $1.0 \times 10^{-4}$, (d) $1.0 \times 10^{-3}$, and (e) $8.0 \times 10^{-3} \mathrm{~mol} \mathrm{~L}^{-1} 2,6$-DNP solutions with (a) blank solution in between.
[29]. Larger cavities and weaker polymer-analyte interactions will result in faster diffusion. Linking curcumin moieties to the backbone of polymer made the cavities generated between adjacent polymers are sufficiently large enough to allow rapid and facile diffusion of small analyte molecules, to the entity of polymer, and simultaneously, the supramolecular recognition interaction between the electron-rich polymer and the electron-deficient analyte was quiet reversible, all of which were responsible for the distinctly fast response of the sensing membrane.

\subsubsection{Repeatability and reproducibility}

The sensor repeatability and reproducibility were calculated according to the definition by Alabbas et al. [30]. The R.S.D. for repeatability of the sensor for the measurement of 2,6-DNP concentration of $5.0 \times 10^{-5} \mathrm{~mol} \mathrm{~L}^{-1}$ and $5.0 \times 10^{-6} \mathrm{~mol} \mathrm{~L}^{-1}$ was calculated to be $1.2 \%$ and $1.1 \%$, respectively. On the other hand, the reproducibility was found to have a R.S.D. value of $3.0 \%$ for 2,6-DNP concentration of $5.0 \times 10^{-5} \mathrm{~mol} \mathrm{~L}^{-1}$ and $4.1 \%$ for 2,6-DNP concentration of $5.0 \times 10^{-6} \mathrm{~mol} \mathrm{~L}^{-1}$.

\subsubsection{Lifetime}

The stability of the sensor was tested by recording the fluorescence intensity of $5.0 \times 10^{-5} \mathrm{~mol} \mathrm{~L}^{-1} 2,6$-DNP over a period of $8 \mathrm{~h}$ for 50 measurements. A relative standard deviation of the fluorescence reading of $1.0 \%$ was recorded. No decrease of the fluorescence intensity of the membrane was observed after a continuous 150 measurement. The sensing membrane exhibited neither bleaching of the fluorophore, chemical decomposition, nor peeling-off of the polymer layer from the glass support for a period of longer than 5 months when stored in buffer solution in the dark at room temperature. The increase of the stability and lifetime of the sensor was resulted from its effective protection from backbone of PVC.

\subsubsection{Selectivity}

To define the response of the sensor to other nitrophenols, different concentrations of 2,6-DNP, $o$-NP, $m$-NP, $p$-NP, 2,4-DNP, and 2,4,6-TNP solutions were pumped to the flow cell separately and the fluorescence intensity was recorded. In Fig. 5, the response parameter, $\alpha$, at $\mathrm{pH} 3.50$, are plotted as functions of the concentrations logarithms of 2,6-DNP and other nitrophenols. The curve fittings for the experimental points were calculated by assuming a 1:1 complex ratio. The optical selectivity coefficients, $\log K^{\text {opt }}$ values [31] are summarized in Table 2. From Fig. 5 and Table 2, we can see that the response of the sensor toward nitrophenols decreases in the order of $2,6-\mathrm{DNP} \gg 2,4-\mathrm{DNP}>p-\mathrm{NP}>m-\mathrm{NP}>o-\mathrm{NP}>$ 2,4,6-TNP.

The effects of other potential interferences such as phenols except for nitrophenols, amines, organic acids, alcohols, and some ions were tested for their possible co-occurrences in environmental or industrial samples with 2,6-DNP. The tolerance limit is set as the concentration of interferences that produces a relative error of less than $\pm 5 \%$ in the apparent recovery of $5.0 \times 10^{-5} \mathrm{~mol} \mathrm{~L}^{-1} 2,6-\mathrm{DNP}$. The results are summarized in 


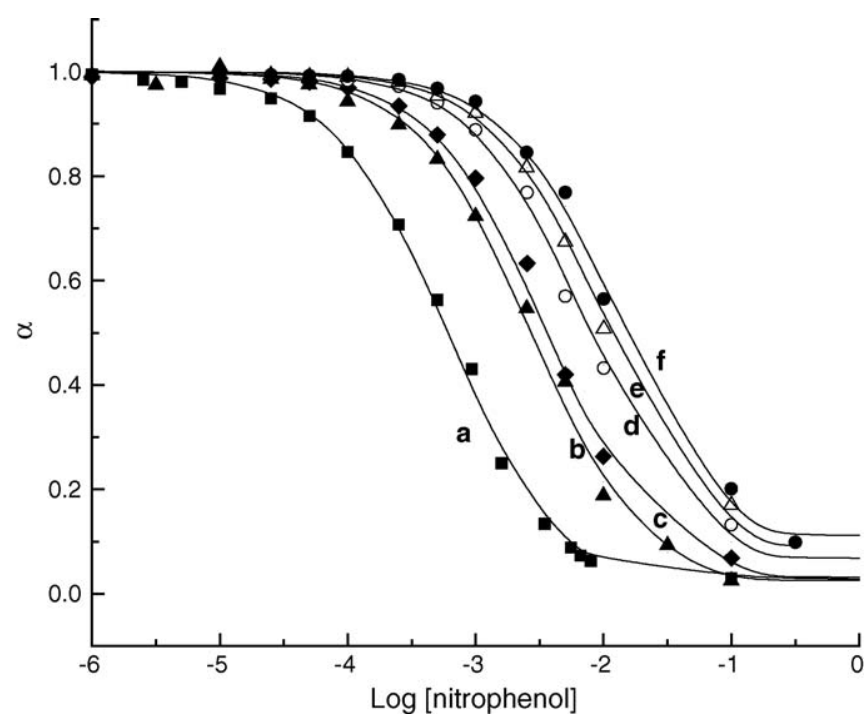

Fig. 5. Response function of the sensing membrane on exposure to various aqueous solutions of nitrophenols measured at $\mathrm{pH} 3.50$ and at an excitation wavelength of $460 \mathrm{~nm}$ and an emission wavelength of $503 \mathrm{~nm}$ : (a) 2,6-DNP; (b) 2,4-DNP; (c) $p$-NP; (d) $m$-NP; (e) $o$-NP; (f) 2,4,6-TNP. The solid lines were calculated according to Eq. (1).

Table 3. As can be seen, many possibly coexisting substances in environmental water showed no remarkable interference for the determination of 2,6-DNP even at high concentration. The limiting water solubility of the tested phenols precluded their higher concentration interference determination. The most serious interference come from $\mathrm{Cr}_{2} \mathrm{O}_{7}{ }^{2-}$ and $\mathrm{MnO}_{4}{ }^{-}$, which were anionic oxidants with color and can be eliminated through a column packed with anionic-exchange resins.

In order to clarify the specific sensing properties of the proposed sensor, the comparison of the sensing characteristics in determining 2,6-DNP between the proposed curcumin substituted PVC sensor and a curcumin embedded sensor was carried out under the same experimental conditions, even though the latter was reported to show high selectivity to $o$-nitrophenol [10]. The results were shown in Table 4. As can be seen, the proposed sensor exhibited apparent advantages over the embedded sensor in terms of sensitivity, selectivity, response time, and lifetime, which almost covers the whole scope of sensor characteristics. The results also reconfirmed the nucleophilic substitution of PVC by curcumin and the distinct sensing ability of FPVC.

Table 2

Association constants $(K)$ and selectivity coefficients $\left(\log K^{\text {opt }}\right)$ of the sensing membrane for other nitrophenols in comparison to 2,6-DNP at pH 3.50

\begin{tabular}{llc}
\hline Interfering agent & $K\left(\mathrm{~mol} \mathrm{~L}^{-1}\right)$ & $\log K^{\text {opt }}$ \\
\hline $2,6-\mathrm{DNP}$ & $2.0 \times 10^{3}$ & 0 \\
$2,4-\mathrm{DNP}$ & $7.3 \times 10^{2}$ & -1.14 \\
$p$-NP & $4.4 \times 10^{2}$ & -1.23 \\
$m$-NP & $3.1 \times 10^{2}$ & -1.61 \\
$o$-NP & $1.9 \times 10^{2}$ & -1.81 \\
$2,4,6-\mathrm{TNP}$ & $0.42 \times 10^{2}$ & -1.92 \\
\hline
\end{tabular}

Table 3

Effect of different phenols and possible interference on the determination of $0.05 \mathrm{mM}$ 2,6-DNP in $\mathrm{pH} 3.50$ buffer solution

\begin{tabular}{|c|c|c|}
\hline Interference & $\begin{array}{l}\text { Tolerance limit } \\
\text { (molar ratio) }\end{array}$ & $\begin{array}{l}\text { Fluorescence } \\
\text { variation }\end{array}$ \\
\hline \multicolumn{3}{|l|}{ Phenols } \\
\hline Pyrocatechol, resorcinol & 300 & + \\
\hline$m$-Cresol, 2,6-xylenol & 250 & + \\
\hline Phenol, o-cresol, hydroquinone & 200 & + \\
\hline$p$-Cresol & 180 & + \\
\hline 2,4-Xylenol, 2-naphthol, pyrogallol & 150 & + \\
\hline 2,4,6-Trinitrophenol & & - \\
\hline $\begin{array}{l}\text { p-Chlorophenol, 2,4-dichlorophenol, } \\
\text { 2,6-dichlorophenol, 1-naphthol }\end{array}$ & 120 & + \\
\hline 2,4,6-Trichlorophenol & & - \\
\hline Salicylic acid & 100 & - \\
\hline$o$-Nitrophenol & 80 & - \\
\hline$m$-Nitrophenol, $p$-nitrophenol & 60 & - \\
\hline 2,4-Dinitrophenol & 50 & - \\
\hline \multicolumn{3}{|l|}{ Cationic ions } \\
\hline $\begin{array}{l}\mathrm{Na}^{+}, \mathrm{K}^{+}, \mathrm{NH}_{4}^{+}, \mathrm{Ag}^{+}, \mathrm{Mn}^{2+}, \mathrm{Ni}^{2+} \\
\mathrm{Mg}^{2+}, \mathrm{Ca}^{2+}, \mathrm{Sr}^{2+}, \mathrm{Ba}^{2+}, \mathrm{Zn}^{2+}, \mathrm{Fe}^{2+} \\
\mathrm{Cu}^{2+}, \mathrm{Cd}^{2+}, \mathrm{Pb}^{2+}, \mathrm{Hg}^{2+}, \mathrm{Al}^{3+}, \mathrm{Fe}^{3+}\end{array}$ & 1000 & a \\
\hline $\mathrm{Co}^{2+}, \mathrm{Cr}^{3+}$ & 200 & - \\
\hline \multicolumn{3}{|l|}{ Anionic ions } \\
\hline $\begin{array}{l}\mathrm{F}^{-}, \mathrm{Cl}^{-}, \mathrm{Br}^{-}, \mathrm{I}^{-}, \mathrm{NO}_{3}{ }^{-}, \mathrm{NO}_{2}{ }^{-} \\
\mathrm{ClO}_{3}{ }^{-}, \mathrm{BrO}_{3}{ }^{-}, \mathrm{HCOO}^{-}, \mathrm{CH}_{3} \mathrm{COO}^{-} \\
\mathrm{IO}_{4}{ }^{-}, \mathrm{S}^{2-}, \mathrm{SO}_{4}{ }^{2-}, \mathrm{SO}_{3}{ }^{2-}, \mathrm{S}_{2} \mathrm{O}_{3}{ }^{2-} \\
\mathrm{SiO}_{3}{ }^{2-}, \mathrm{CO}_{3}{ }^{2-}, \mathrm{C}_{2} \mathrm{O}_{4}{ }^{2-}, \mathrm{MoO}_{4}{ }^{2-} \\
\mathrm{PO}_{4}{ }^{3-}, \mathrm{AsO}_{4}{ }^{3-}\end{array}$ & 1000 & a \\
\hline $\mathrm{Cr}_{2} \mathrm{O}_{7}^{2-}$ & 15 & - \\
\hline $\mathrm{MnO}_{4}^{-}$ & 8 & - \\
\hline \multicolumn{3}{|l|}{ Organic acids } \\
\hline $\begin{array}{l}\text { Formic acid, propionic acid, } n \text {-butyric } \\
\text { acid, succinic acid, tartaric acid, citric } \\
\text { acid, lactic acid, } p \text {-toluenesulfonic } \\
\text { acid, } p \text {-phthalic acid, DL-malic acid }\end{array}$ & 1000 & a \\
\hline \multicolumn{3}{|l|}{ Others } \\
\hline Glucose, boric acid, urea & 1000 & $\mathrm{a}$ \\
\hline Aniline, humic acid & 100 & - \\
\hline
\end{tabular}

- , Fluorescence decrease; +, fluorescence increase.

a No interference.

Table 4

Comparison of sensing characteristics between the two sensors for 2,6-DNP determination

\begin{tabular}{lll}
\hline Sensors & The proposed sensor & $\begin{array}{l}\text { The curcumin } \\
\text { embedded sensor }\end{array}$ \\
\hline $\begin{array}{l}\text { Membrane matrices } \\
\text { Sensing substances }\end{array}$ & $\begin{array}{l}\text { No matrices } \\
\text { Curcumin substituted PVC }\end{array}$ & $\begin{array}{l}\text { PVC } \\
\text { Curcumin }\end{array}$ \\
Dynamic range $\left(\mathrm{mol} \mathrm{L}^{-1}\right)$ & $2.5 \times 10^{-6}$ to $7.0 \times 10^{-3}$ & $8.0 \times 10^{-4}$ to \\
& & $1.0 \times 10^{-3}$ \\
Detection limit $\left(\mathrm{mol} \mathrm{L}^{-1}\right)$ & $1.0 \times 10^{-6}$ & $6.0 \times 10^{-4}$ \\
Response time $\left(t_{95}\right)(\mathrm{s})$ & 50 & 100 \\
Lifetime $^{\mathrm{a}}(\%)$ & 0 & 20
\end{tabular}

${ }^{a}$ Fluorescence intensity decrease percent after a continuous 200 measurements. 


\subsection{Sensing mechanism}

Suppose that the curcumin moiety in FPVC remains the keto-enol tautomeric equilibrium of curcumin molecule [32], i.e.,<smiles>[R]C(=O)CC([R])=O</smiles>

(I) keto form<smiles>C=C</smiles><smiles>[R]C(=O)C=C([R])O</smiles>

(II) enol form

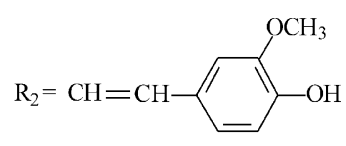

$\mathrm{CH}$
So it is possible for hydroxyl or carbonyl groups to form associated complexes by the means of hydrogen bond with some compounds containing hydroxyl or nitro group.

As the stoichiometric ratio of the tested nitrophenols to FPVC was proved to be $1: 1$ and 2,6-DNP exists mainly in the molecular form at $\mathrm{pH} 3.50$, it seems that the hydroxyl and nitro-groups in 2,6-DNP simultaneously associate with the carbonyl and hydroxyl groups of enol form of FPVC through hydrogen bond to form non-fluorescent ground state complex, i.e.,
(II)<smiles>O=[N+]([O-])c1cccc([N+](=O)[O-])c1O</smiles>

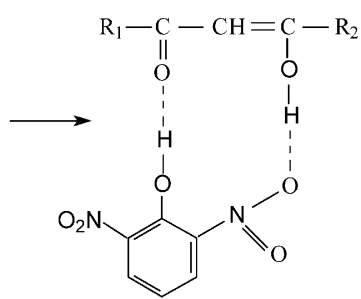

(III)
The formation of the cyclic structure III causes the fluorescence quenching of FPVC.

The 2,6-DNP selectivity of this sensing membrane was based on the ability difference between 2,6-DNP and other nitrophenols in forming the cyclic non-fluorescent complex with FPVC through hydrogen bonding. Two factors, including the steric hindrance and acidity of nitrophenols, must be considered. The steric hindrance, or spatial matching effect, was predominated by the cavity size of polymer and the molecular structure of the analyte. The ionisation constant $\left(\mathrm{p} K_{\mathrm{a}}\right)$ was the indicator for acidity of nitrophenols, which was summarized in Table 5. As can be seen from Table 5, under the experimental $\mathrm{pH}$, the tested nitrophenols were all in their molecular form except 2,4,6-TNP. The solution $\mathrm{pH}$ of 3.50 deprotonated its phenolic hydroxy group and it is mainly in the anion form such that inclined to stay in the solution and not to diffuse into the membrane phase. In addition, the steric hindrance experienced by 2,4,6-TNP because of its three-dimensional molecular structure [35] may also block its migration into the membrane phase and react with the sensing materials. So FPVC showed the smallest response to 2,4,6-TNP. $o$-NP was very much more intramolecularly hydrogen bonded than other nitrophenols [36], which may form a unfavorable molecular structure for its effective interaction with FPVC to
Table 5

Ionisation constant $\left(\mathrm{p} K_{\mathrm{a}}\right)$ of tested nitrophenols

\begin{tabular}{ll}
\hline Nitrophenols & $\mathrm{p} K_{\mathrm{a}}$ \\
\hline$o$-NP & $7.23^{\mathrm{a}}$ \\
$m$-NP & $8.39^{\mathrm{a}}$ \\
$p$-NP & $7.15^{\mathrm{a}}$ \\
$2,4-\mathrm{DNP}$ & $4.09^{\mathrm{a}}$ \\
$2,6-\mathrm{DNP}$ & $3.68^{\mathrm{b}}$ \\
$2,4,6-\mathrm{TNP}$ & $0.71^{\mathrm{c}}$ \\
\hline
\end{tabular}

${ }^{\text {a }}$ Data taken from [33].

b Data taken from [26].

${ }^{\mathrm{c}}$ Data taken from [34].

form the non-fluorescent complex. The similar phenomenon also occurred to 2,4-DNP, i.e.,

(II) +

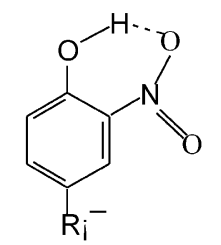<smiles>[R]CC</smiles>

$$
\begin{aligned}
& \mathrm{R}^{\prime}=\mathrm{H}, \quad o-\mathrm{NP} \\
& \mathrm{R}^{\prime}=\mathrm{NO}_{2}, 2,4-\mathrm{DNP}
\end{aligned}
$$<smiles>[R]C(=CC(=O)I)O[TlH]O[N+]([O-])(O)Oc1ccc([R7])cc1[R]</smiles>

It is apparent that the 3- and 4-position nitro groups in $m$ - and $p$-NP may offer disadvantageous configuration for their effective interaction with FPVC through hydrogen bond and their response was relatively small.
(II) +<smiles>O=[N+]([O-])c1cccc(O)c1</smiles><smiles>[R]C([R])=CC([R])O</smiles>

(II) +<smiles>O=[N+]([O-])c1ccc(O)cc1</smiles><smiles>[R]C(=O)C=C([R])O[Hg]Oc1ccc([N+](=O)[O-])cc1</smiles>

(VI)
It can be seen that the spatial adaptability between the analytes and sensing substance showed the dominating effect on their effective interaction in the proposed chemical sensor. 2,6DNP possesses a most spatially matching structure for its migra- 
Table 6

Analytical results for 2,6-DNP in water samples $(n=5)$

\begin{tabular}{|c|c|c|c|c|c|}
\hline \multirow[t]{2}{*}{ Sample } & \multirow[t]{2}{*}{ Nitrophenols added $\left(10^{-5} \mathrm{~mol} \mathrm{~L}^{-1}\right)$} & \multicolumn{2}{|c|}{ 2,6-DNP found $\left(10^{-5} \mathrm{~mol} \mathrm{~L}^{-1}\right)$} & \multicolumn{2}{|l|}{ Recovery $(\%)$} \\
\hline & & Proposed sensor & HPLC method [7] & Proposed sensor & HPLC method [7] \\
\hline Tap water 1 & $\begin{array}{l}o \text {-NP, } 0.2 ; m \text {-NP, } 0.15 ; p \text {-NP, } 0.3 ; 2,4 \text {-DNP, } \\
0.15 ; 2,6-\mathrm{DNP}, 0.2 ; 2,4,6-\mathrm{TNP}, 0.1\end{array}$ & $0.21 \pm 0.01$ & $0.20 \pm 0.01$ & 105 & 100 \\
\hline Tap water 2 & $\begin{array}{l}o \text {-NP, } 0.3 ; m \text {-NP, } 0.15 ; p \text {-NP, } 0.3 ; 2,4-\mathrm{DNP}, \\
0.15 ; 2,6 \text {-DNP, } 0.3 ; 2,4,6 \text {-TNP, } 0.1\end{array}$ & $0.32 \pm 0.02$ & $0.31 \pm 0.01$ & 107 & 103 \\
\hline River water 1 & $\begin{array}{l}o \text {-NP, } 1.0 ; m-\mathrm{NP}, 1.5 ; p \text {-NP, } 1.0 ; 2,4-\mathrm{DNP} \\
1.5 ; 2,6-\mathrm{DNP}, 5.0 ; 2,4,6-\mathrm{TNP}, 1.5\end{array}$ & $4.7 \pm 0.2$ & $4.8 \pm 0.1$ & 94 & 96 \\
\hline River water 2 & $\begin{array}{l}o \text {-NP, } 1.0 ; m-\mathrm{NP}, 1.0 ; p \text {-NP, } 0.8 ; 2,4-\mathrm{DNP} \\
1.2 ; 2,6-\mathrm{DNP}, 1.0 ; 2,4,6-\mathrm{TNP}, 0.8\end{array}$ & $1.1 \pm 0.2$ & $1.1 \pm 0.2$ & 110 & 110 \\
\hline
\end{tabular}

tion through the polymer cavity and approach the fluorophore to form a supramolecular complex.

\subsection{Preliminary analytical application}

The proposed sensor was applied to the determination of 2,6DNP in tap and river water samples in the presence of other nitrophenols. River water samples were first acidified by sulphuric acid to $\mathrm{pH} 3.50$, then filtered through a $0.45-\mu \mathrm{m}$ filter membrane (Ya Dong Nuclear Grade Resins Co. Ltd., Shanghai Institute of Pharmaceutical Industry, Shanghai, China) and a column packed with anionic-exchange resin (Amberlite IRA-400, USA), successively. Tap water samples were acidified to $\mathrm{pH} 3.50$ and analyzed without any pretreatment. All the water samples were spiked with nitrophenols at different concentration levels and then analyzed. The results obtained for 2,6-DNP determination were also compared with those obtained by HPLC method [7] and were shown in Table 6. We can see that the results were satisfactory. The present sensor may be useful for the determination of 2,6-DNP in real samples.

\section{Conclusions}

A novel functional polymer has been successfully synthesized by the nucleophilic substitution of a fraction of the chlorine atoms bound to the PVC backbone by curcumin. The polymer was applied to fabricate an optical fiber chemical sensor for the determination of 2,6-DNP simply, quickly, and selectively. The fluorescence signal variation was very reversible and was proportional to 2,6-DNP concentration. As 2,6-DNP can provide an optimal space geometry matches to the formation of a cyclic complex with low fluorescence efficiency, the sensor shows excellent selectivity for 2,6-DNP. The response time, repeatability, and lifetime of the sensor were also satisfied. The study results enabled better understanding of the interaction between functional polymer and the analytes and prove useful in the future development of high-quality chemical sensors for on line environmental monitoring.

\section{Acknowledgements}

The authors gratefully acknowledge financial support of the National Science Fund for Distinguished Young Scholars of
China (No. 20125514), National Natural Science Foundation of China (No. 20437020, 50273046) and Major Research Program of Chinese Academy of Sciences (KZCX3-SW-432).

\section{References}

[1] D.M. Nevskaia, E. Castillejos-Lopez, V. MuÑoz, A. Guerrero-Ruiz, Environ. Sci. Technol. 38 (2004) 5786.

[2] M.L. Davi, F. Gnudi, Water Res. 33 (1999) 3213.

[3] U.S., Environmental Protection Agency (EPA), National Recommended Water Quality Criteria, 2004.

[4] B. Swarnalatha, Y. Anjaneyulu, J. Mol. Catal. A: Chem. 223 (2004) 161.

[5] R. Belloli, B. Barletta, E. Bolzacchini, S. Meinardi, M. Orlandi, B. Rindone, J. Chromatogr. A 846 (1999) 277.

[6] D. Kaniansky, E. Krčmová, V. Madajová, M. Masár, J. Marák, F.I. Onuska, J. Chromatogr. A 772 (1997) 327.

[7] H. Roseboom, C.J. Berkhoff, J.I.J. Wammes, R.C.C. Wegman, J. Chromatogr. 208 (1981) 331.

[8] H. Sohn, R.M. Calhoun, M.J. Sailor, W.C. Trogler, Angew. Chem. Int. Ed. 40 (2001) 2104.

[9] X. Yang, C.G. Niu, G.L. Shen, R.Q. Yu, Analyst 126 (2001) 349.

[10] Y. Wang, K.M. Wang, G.L. Shen, R.Q. Yu, Talanta 44 (1997) 1319.

[11] B. Adhikari, S. Majumdar, Prog. Polym. Sci. 29 (2004) 699.

[12] A. Mirmohseni, A. Oladegaragoze, Sens. Actuators B 102 (2004) 261.

[13] I. Varga, R. Mészáros, Z. Szakács, T. Gilányi, Langmuir 21 (2005) 6154.

[14] S. Lakshmi, A. Jayakrishnan, Polymer 39 (1998) 151.

[15] S. Lakshmi, A. Jayakrishnan, Biomaterials 23 (2002) 4855.

[16] P.V.C. Rao, V.K. Kaushik, I.S. Bhardwaj, Eur. Polym. J. 31 (1995) 341.

[17] M. Rogestedt, T. Hjertberg, Macromolecules 26 (1993) 60.

[18] J.L. Koenig, M.K. Antoon, J. Polym. Sci.: Polym. Phys. Ed. 15 (1977) 1379.

[19] D. Fabbri, D. Tartari, C. Trombini, Anal. Chim. Acta 413 (2000) 3.

[20] F. Sittner, B. Enders, W. Ensinger, Thin Solid Films 459 (2004) 233.

[21] T. Rosatzin, P. Holỳ, K. Seiler, B. Rusterholz, W. Simon, Anal. Chem. 64 (1992) 2029.

[22] N.U. Perišic-Janjic, A.A. Muk, V.D. Canic, Anal. Chem. 45 (1973) 798.

[23] S.V. Jovanovic, S. Steenken, C.W. Boone, M.G. Simic, J. Am. Chem. Soc. 121 (1999) 9677.

[24] J. Crank, G.S. Park, Diffusion in Polymers, Academic Press, London, 1968 , p. 21

[25] X.B. Zhang, C.C. Guo, Z.Z. Li, G.L. Shen, R.Q. Yu, Anal. Chem. 74 (2002) 821

[26] G. Nalecz-Jawecki, J. Sawicki, Chemosphere 52 (2003) 249.

[27] M.M.F. Choi, X.J. Wu, Y.R. Li, Anal. Chem. 71 (1999) 1342.

[28] D.S. Blair, L.W. Burgess, A.M. Brodsky, Anal. Chem. 69 (1997) 2238.

[29] J.S. Yang, T.M. Swager, J. Am. Chem. Soc. 120 (1998) 11864. 
[30] S.H. Alabbas, D.C. Ashworth, R. Narayanaswamy, Anal. Proc. 26 (1989) 373.

[31] R.H. Yang, K.A. Li, F. Liu, N. Li, F.L. Zhao, W.H. Chan, Anal. Chem. 75 (2003) 3908

[32] G. Litwinienko, K.U. Ingold, J. Org. Chem. 69 (2004) 5888.
[33] M. Czaja, A. Kozak, M. Makowski, L. Chmurzynski, J. Chem. Thermodyn. 35 (2003) 1645

[34] S.G. Dmitrienko, E.N. Myshak, L.N. Pyatkova, Talanta 49 (1999) 309. [35] M.H. Abraham, C.M. Du, J.A. Platts, J. Org. Chem. 65 (2000) 7114.

[36] B. Müller, M.R. Heal, J. Phys. Chem. A 106 (2002) 5120. 